\title{
Synergistic effects of telmisartan and pyridoxamine on early renal damage in spontaneously hypertensive rats
}

\author{
PENGLI ZHU ${ }^{1 *}$, HONG LIN $^{1,2^{*}}$, CHENGAI SUN ${ }^{1,3^{*}}$, FAN LIN $^{1}$, HUIZHEN YU $^{1}$, \\ XIUPING ZHUO $^{1}$, CHANJUAN ZHOU ${ }^{1}$ and ZHISHENG DENG ${ }^{1}$

\begin{abstract}
${ }^{1}$ Department of Geriatrics, Fujian Provincial Hospital, Fujian Institute of Clinical Geriatrics, Fujian Medical University, Fuzhou, Fujian 350001; ${ }^{2}$ Department of Nursing, Xiamen Medical College, Xiamen, Fujian 361000;

${ }^{3}$ Department of Emergency, The Second People's Hospital of Lianyungang, Lianyungang, Jiangsu 222300, P.R. China
\end{abstract}

Received September 23, 2011; Accepted December 12, 2011

DOI: $10.3892 / \mathrm{mmr} .2011 .717$

\begin{abstract}
The aim of this study was to investigate the protective effects of telmisartan and/or pyridoxamine on spontaneously hypertensive rats (SHRs). Rats were treated with telmisartan ( $\mathrm{T}$ group) or pyridoxamine ( $\mathrm{P}$ group), or telmisartan and pyridoxamine (TP group). The serum levels of advanced glycation end products (AGEs), superoxide dismutase (SOD), malonaldehyde and the level of 24-h urinary albumin were measured. Morphological changes in renal tissues were observed under light (H\&E or Masson's trichrome) and transmission electron microscopy. Expression of NF- $\mathrm{NBp} 65$ and p-ERK1/2 in renal tissue was detected by immunohistochemistry. Expression of receptors for advanced glycation end products (RAGE) and TGF- $\beta$ in the renal cortex was investigated by western blotting. We found that early renal structural and functional damage was alleviated in the three intervention groups. SOD activity was significantly elevated in the $\mathrm{P}$ and TP groups $(\mathrm{P}<0.05)$ compared to that in the $\mathrm{T}$ group. Of note, both the positive expression of $\mathrm{NF}-\kappa \mathrm{Bp} 65(\mathrm{P}<0.01 \mathrm{vs}$. the $\mathrm{T}$ and $\mathrm{P}$ groups) and $\mathrm{p}-\mathrm{ERK} 1 / 2(\mathrm{P}<0.05$ vs. the $\mathrm{P}$ group) was lowest in the TP group. Our results suggest that the combined use of telmisartan and pyridoxamine is superior to the single use of either drug on renoprotection, which may result from the alleviation of oxidative stress and the reduction of NF- $\kappa \mathrm{Bp} 65$ and p-ERK1/2 activation.
\end{abstract}

\section{Introduction}

The mechanisms of hypertensive renal damage include hypertension-induced hemodynamic changes and the release

Correspondence to: Dr Pengli Zhu, Department of Geriatrics, Fujian Provincial Hospital, 134 East Street, Fuzhou, Fujian 350001, P.R. China

E-mail: zhu_pengli@yahoo.cn

\section{${ }^{*}$ Contributed equally}

Key words: advanced glycation end products, pyridoxamine, telmisartan, oxidative stress, renin-angiotensin system of cytokines by vascular endothelial cells. Previous studies have shown that advanced glycation end products (AGEs) and the receptors for advanced glycation end products (RAGE) are involved in the pathophysiology of essential hypertension, and promote the progression of hypertension and end-organ damage (1-5). However, it remains unclear how AGEs and RAGE are involved in the progression of early renal damage in essential hypertension, and whether the inhibition of AGE formation reduces early hypertensive renal damage. There is considerable interest in the interaction between the renin-angiotensin system (RAS) and AGEs-RAGE in hypertension. In vitro (6) experiments have shown that AGEs increase chymase expression in vascular smooth muscle cells through the ERK1/2-MAPK signal transduction pathway, which results in an increased production of angiotensin II synthesized through the chymase pathway. Subsequently, the binding of angiotensin II to angiotensin type-1 (AT1) receptors was found to increase the expression of RAGE, which in turn promoted the binding of AGEs and RAGE (7). In addition, a mutually reinforcing relationship was noted between oxidative stress, AGEs-RAGE and RAS, which was found to aggravate the progression of hypertension and damage of target organs (8-11).

Pyridoxamine is one of the three natural forms of vitamin B6. Studies have shown that pyridoxamine strongly inhibits the production of AGEs both in vitro and in vivo $(12,13)$. Pyridoxamine is also a free radical scavenger. It eliminates the reactive oxygen species (ROS) produced by biochemical reactions in the body, thereby reducing oxidative stress. Telmisartan has the strongest binding affinity to angiotensin II receptors among all angiotensin II receptor blockers (14). It binds to the AT1 subtype with high affinity, and the binding persists for an extensive period of time without any partial agonist effects. Telmisartan also activates peroxisome proliferator-activated receptor $\gamma$ (PPAR $\gamma)(15)$, which acts as a transcription factor regulating the expression of multiple genes related to carbohydrate, lipid metabolism and inflammation. Previous animal experiments have shown that the combined use of pyridoxamine and enalapril (angiotensin converting enzyme inhibitor; ACEI) reduces renal damage in type 2 diabetes (16). However, there have been no reports on the effects of pyridoxamine on early renal 
damage in spontaneously hypertensive rats (SHRs). Therefore, SHRs were used in this study to investigate the differences between the single and the combined use of telmisartan and pyridoxamine.

\section{Materials and methods}

Animal grouping. Forty-eight SPF-grade SHRs (male, 20 weeks of age) weighing 350-450 g were randomly divided into four groups with 12 animals in each group. The hypertension control (HC) group received gastric lavage with $2 \mathrm{ml}$ distilled water once per day. The telmisartan (T) group received gastric lavage with $6 \mathrm{mg} / \mathrm{kg}$ telmisartan (Boehringer Ingelheim, Germany) dissolved in $2 \mathrm{ml}$ of distilled water once per day. The pyridoxamine $(\mathrm{P})$ group received gastric lavage with $200 \mathrm{mg} / \mathrm{kg}$ pyridoxamine hydrochloride (Biofer, USA) dissolved in $2 \mathrm{ml}$ of distilled water once per day. The telmisartan snd pyridoxamine (TP) group received gastric lavage with $6 \mathrm{mg} / \mathrm{kg}$ telmisartan and $200 \mathrm{mg} / \mathrm{kg}$ pyridoxamine hydrochloride dissolved in $2 \mathrm{ml}$ of distilled water once per day. The normal control (NC) group included $13 \mathrm{WKY}$ rats (male, 20 weeks of age) weighing 300-400 g and received gastric lavage with $2 \mathrm{ml}$ of distilled water once per day. The animals were weighed once per week and the intervention was continued for 16 weeks. The rats were purchased from Slac Laboratory Animal, Co., Ltd., Shanghai, China [license no.: SCXK (Hu) 2007-0005]. The rats were raised in the SPF system at the Experimental Animal Center of the Fujian Medical University [license no.: SYXK (Min) 2008-0001]. The protocols for animal handling and experimentation were in accordance with the principles established by the Animal Welfare Committee of Fujian Medical University.

Blood pressure measurements and detection of serum and tissue biochemical indicators. An intelligent non-invasive hemodynamometer (BP-98AL; Softron, Tokyo, Japan) was used to measure systolic blood pressure (SBP) in the rat tail artery. The SBP was taken once biweekly. At 16 weeks, the rats were placed in a metabolic cage and a 24-h urine sample was collected to measure the urinary albumin concentration. Blood samples were collected before the animals were sacrificed. An automatic biochemical analyzer (LX20; Beckman Coulter, Inc., Brea, CA, USA) was used to measure serum creatinine and urea nitrogen. Immune nephelometry was performed to measure the concentration of 24-h urinary albumin.

The measurement of AGEs, malonaldehyde and superoxide dismutase (SOD) was performed according to the manufacturer's instructions. Serum AGEs were determined using ELISA (ELISA kit; R\&D, USA). Serum malonaldehyde was determined with the thiobarbituric-acid method (malonaldehyde detection kit; Nanjing Jiancheng Bioengineering Institute, China); SOD activity was determined in serum and renal tissue homogenates with the xanthine-oxidase method (SOD Detection kit; Nanjing Jiancheng Bioengineering Institute).

Renal tissue morphology and immunohistochemical detection of $N F-\kappa B p 65$ and $p-E R K 1 / 2$. Paraffin sections with a thickness of $3 \mu \mathrm{m}$ were stained with H\&E or Masson's trichrome. The stained samples were examined under light microscope and photographed (DP-71; Olympus, Tokyo, Japan). Ultra-thin sections stained with uranyl acetate and lead citrate were placed under a transmission electron microscope and photographed (Hu-12A; Hitachi, Tokyo, Japan) to observe the glomerular filtration membrane, mesangial region and renal tubules. Immunohistochemical examination was performed using a rabbit super-sensitive 2-step immunohistochemical detection kit (PV-9001; Zhongshan Goldenbridge Biochemistry, Co., Ltd., Beijing, China). Sections were routinely treated with $3 \%$ $\mathrm{H}_{2} \mathrm{O}_{2}$ to inactivate endogenous peroxidase, and the antigen was retrieved with the micro-boiling antigen retrieval method. After blocking with 5\% BSA, rabbit anti-NF- $\kappa$ Bp65, anti-pERK1/2 monoclonal antibodies (Santa Cruz Biotechnology, Santa Cruz, CA, USA) were applied, and the sections were incubated at $37^{\circ} \mathrm{C}$. After applying the enhancer, the sections were incubated at room temperature followed by the application of horseradish peroxidase-labeled secondary antibody (Santa Cruz). The tissues were observed after DAB coloration. Ten high-power fields were randomly selected for each section and photographed. To quantify the immunohistochemical results, the mean optical density (MOD) of the brown-yellow or brown positive areas in the section images was measured using Image Pro Plus (version 6.0; Media Cybernetics, Bethesda, MD, USA).

Western blotting. Renal cortical protein was extracted with a total-protein extraction kit (BestBio, Shanghai, China). The protein concentration was determined using the Bradford method. Each well was loaded with $40 \mu \mathrm{g}$ protein for $15 \%$ SDS-PAGE electrophoresis, followed by NC membrane transfer, incubation with the RAGE primary antibody and TGF- $\beta$ primary antibody (Santa Cruz) at room temperature for $2 \mathrm{~h}$, and incubation with horseradish peroxidase-labeled secondary antibody at room temperature for $2 \mathrm{~h}$. Images were developed with SuperHi ${ }^{\mathrm{TM}}$ Chemiluminescence (Columbia Bio LLC, Elmhurst, NY, USA) and photographed under $\mathrm{X}$-ray exposure. The images were analyzed with an imaging analysis system. The ratio of the gray value of target proteins to that of internal control ( $\beta$-actin) was used as the relative protein expression of the target proteins. Each experiment was repeated three times.

Statistical analysis. All the data were analyzed using SPSS 16.0 statistical software. All quantitative data were presented as the means \pm standard deviation. The comparison of multiple groups was performed with one-way analysis of variance (ANOVA) followed by the Student's t-test between two groups. The Mann Whitney U-test was used to compare two groups when the variances were heterogeneous. Pearson's correlation analysis was performed to determine the correlation between the serum levels of AGEs and the concentration of 24-h urinary albumin. The SBPs were compared over time with repeated measures ANOVA followed by a Bonferroni test for post-hoc analysis. $\mathrm{P}<0.05$ (two-tailed) indicates a statistically significant difference.

\section{Results}

SBPs in the tail artery. Prior to intervention, the baseline SBPs in the HC, T, P and TP groups were 193.3 $\pm 13.0,192.4 \pm 13.3$, $190.6 \pm 11.8$ and $193.6 \pm 13.2 \mathrm{mmHg}$, respectively. There was 

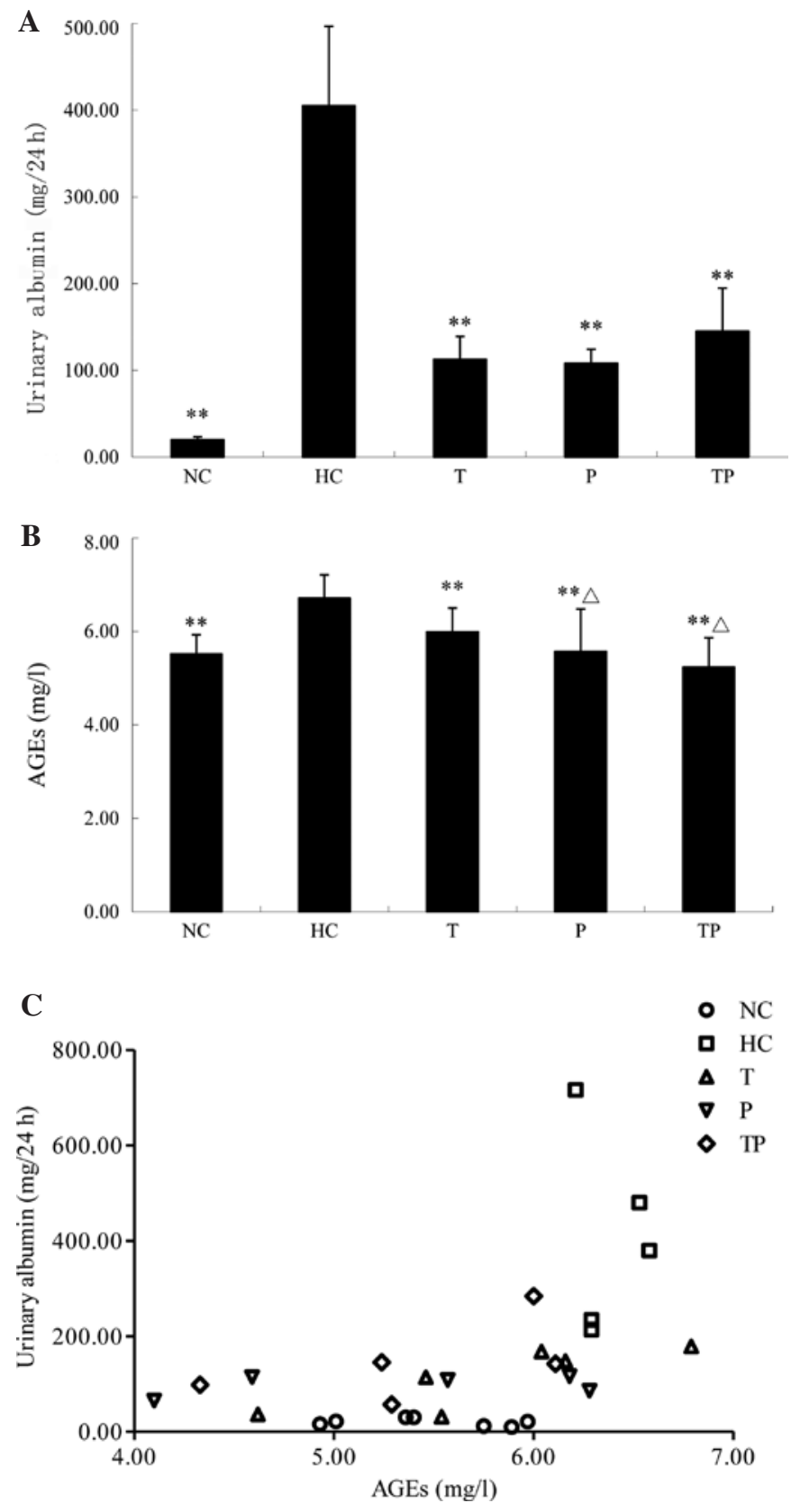

Figure 1. Renal function and the serum advanced glycation end products (AGEs). (A) Urinary albumin and (B) AGEs at the 16th week by group. (C) Scatter plot of urinary albumin (y-axis) and serum AGEs (x-axis). $\mathrm{NC}$, normal control; HC, hypertension control; T, telmisartan; $\mathrm{P}$, pyridoxamine; TP, telmisartan and pyridoxamine. Data are presented as the means $\pm \mathrm{SD}$ of $5-6$ rats/group. ${ }^{* *} \mathrm{P}<0.01$ vs. the $\mathrm{HC}$ group; ${ }^{\triangle} \mathrm{P}<0.05$ vs. the $\mathrm{T}$ group. Pearson's correlation was $0.501(\mathrm{P}<0.01)$.

no significant difference among these values $(\mathrm{P}>0.05)$. All SBPs in the SHRs were higher than those in the NC group $(128.5 \pm 5.8 \mathrm{mmHg})(\mathrm{P}<0.01)$. The SBPs in the T and TP groups were reduced within 2 weeks. Sixteen weeks following the intervention, the SBPs in the T $(99.80 \pm 11.69 \mathrm{mmHg})$ and TP $(97.00 \pm 10.27 \mathrm{mmHg})$ groups were significantly reduced compared to their baseline values $(\mathrm{P}<0.01)$. In addition, the magnitude of SBP reduction in the $\mathrm{T}$ group was similar to that in the TP group $(\mathrm{P}>0.05)$. The SBP in the $\mathrm{P}$ group $(195.37 \pm 20.67 \mathrm{mmHg})$ following intervention was not
Table I. Serum creatinine and blood urea nitrogen at the 16th week by group.

\begin{tabular}{lccc}
\hline Group & $\mathrm{n}$ & $\begin{array}{c}\text { Serum creatinine } \\
(\mathrm{mmol} / \mathrm{l})\end{array}$ & $\begin{array}{c}\text { Blood urea } \\
\text { nitrogen } \\
(\mathrm{mmol} / \mathrm{l})\end{array}$ \\
\hline Normal & 13 & $49.60 \pm 9.99$ & $6.58 \pm 0.72$ \\
Hypertension & 12 & $51.83 \pm 5.19$ & $7.75 \pm 0.88$ \\
Telmisartan & 10 & $52.00 \pm 9.14$ & $7.30 \pm 1.70$ \\
Pyridoxamine & 12 & $49.67 \pm 5.50$ & $7.38 \pm 1.56$ \\
$\begin{array}{l}\text { Telmisartan } \\
+ \text { pyridoxamine }\end{array}$ & 10 & $48.64 \pm 8.56$ & $7.26 \pm 0.69$ \\
\hline
\end{tabular}

There were no significant differences in the serum levels of creatinine or urea nitrogen among the groups $(\mathrm{P}>0.05)$.

significantly different from baseline, which was similar to the

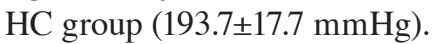

Renal function and the levels of serum AGEs. Following the 16-week intervention, the levels of urinary albumin in the $\mathrm{T}$ (112.68 $\pm 26.54 \mathrm{mg} / 24 \mathrm{~h}), \mathrm{P}(108.33 \pm 15.96 \mathrm{mg} / 24 \mathrm{~h})$ and TP $(145.35 \pm 49.40 \mathrm{mg} / 24 \mathrm{~h})$ groups were significantly lower than those in the HC group (404.94 $\pm 91.84 \mathrm{mg} / 24 \mathrm{~h})(\mathrm{P}<0.01)$. There were no significant differences among the three intervention groups. The serum levels of AGEs in the T $(5.99 \pm 0.51 \mathrm{mg} / \mathrm{l}), \mathrm{P}$ $(5.57 \pm 0.91 \mathrm{mg} / \mathrm{l})$ and TP $(5.24 \pm 0.63 \mathrm{mg} / \mathrm{l})$ groups were lower than those in the HC group $(6.71 \pm 0.50 \mathrm{mg} / \mathrm{l})(\mathrm{P}<0.01)$. In addition, the serum levels of AGEs in the $\mathrm{P}$ and TP groups were lower compared to those in the $\mathrm{T}$ group $(\mathrm{P}<0.05)$, whereas there was no significant difference between the serum levels in the $\mathrm{P}$ and TP groups. Pearson's correlation analysis showed that there was a significant correlation between the serum levels of AGEs and the concentration of 24-h urinary albumin in all of the rats $(r=0.501, P<0.01)$ (Fig. 1). There were no significant differences in the serum levels of creatinine or urea nitrogen among the groups $(\mathrm{P}>0.05)$ (Table I).

Levels of oxidative stress indicators in rat serum and renal cortical tissue. Following intervention for 16 weeks, the activity of serum SOD in the T $(177.73 \pm 11.30 \mathrm{U} / \mathrm{ml}), \mathrm{P}(210.05 \pm 5.70 \mathrm{U} /$ $\mathrm{ml})$ and TP $(211.23 \pm 5.95 \mathrm{U} / \mathrm{ml})$ groups was higher than that in the HC group $(160.16 \pm 14.56 \mathrm{U} / \mathrm{ml})(\mathrm{P}<0.05)$. The SOD activity in the $\mathrm{P}$ and TP groups was higher compared to that in the $\mathrm{T}$ group $(\mathrm{P}<0.05)$. The serum and renal tissue homogenate levels of malonaldehyde in the T, P and TP groups were lower than those in the HC group $(\mathrm{P}<0.05)$. There were no significant differences among the three intervention groups $(\mathrm{P}>0.05)$ (Table II).

Morphological changes in rat renal tissue. In the HC group, H\&E staining showed occasional shrinkage and hardening of the glomeruli, and most of the capillaries showed lumen occlusion with hyaline degeneration, glomerular-capsule adhesion, thickening of the Bowman's capsule wall, atrophy of peripheral renal tubules and protein casts (Fig. 2B, indicated by a black arrow). The epithelial cells of other renal tubules 
Table II. Activities of serum superoxide dismutase and malonaldehyde levels in the serum and renal cortex.

\begin{tabular}{lcccc}
\hline Group & $\mathrm{n}$ & $\begin{array}{c}\text { SOD activity } \\
(\mathrm{U} / \mathrm{ml})\end{array}$ & $\begin{array}{c}\text { Serum malonaldehyde } \\
(\mathrm{nmol} / \mathrm{ml})\end{array}$ & $\begin{array}{c}\text { Renal malonaldehyde } \\
(\mathrm{nmol} / \mathrm{mg})\end{array}$ \\
\hline Normal & 13 & $186.04 \pm 15.07^{\mathrm{a}}$ & $9.72 \pm 0.88^{\mathrm{a}}$ & $26.51 \pm 2.66^{\mathrm{a}}$ \\
Hypertension & 12 & $160.16 \pm 14.56$ & $12.92 \pm 1.87$ & $32.82 \pm 3.47$ \\
Telmisartan & 10 & $177.73 \pm 11.30^{\mathrm{a}}$ & $7.50 \pm 0.94^{\mathrm{a}}$ & $23.91 \pm 2.04^{\mathrm{a}}$ \\
Pyridoxamine & 12 & $210.05 \pm 5.70^{\mathrm{a}, \mathrm{b}}$ & $7.14 \pm 0.85^{\mathrm{a}}$ & $20.59 \pm 2.15^{\mathrm{a}}$ \\
Telmisartan + pyridoxamine & 10 & $211.23 \pm 5.95^{\mathrm{a}, \mathrm{b}}$ & $6.88 \pm 0.41^{\mathrm{a}}$ & $22.44 \pm 5.03^{\mathrm{a}}$ \\
\hline
\end{tabular}

${ }^{\mathrm{a}} \mathrm{P}<0.05$ vs. the $\mathrm{HC}$ group; ${ }^{\mathrm{b}} \mathrm{P}<0.05$ vs. the $\mathrm{T}$ group. $\mathrm{SOD}$, superoxide dismutase.

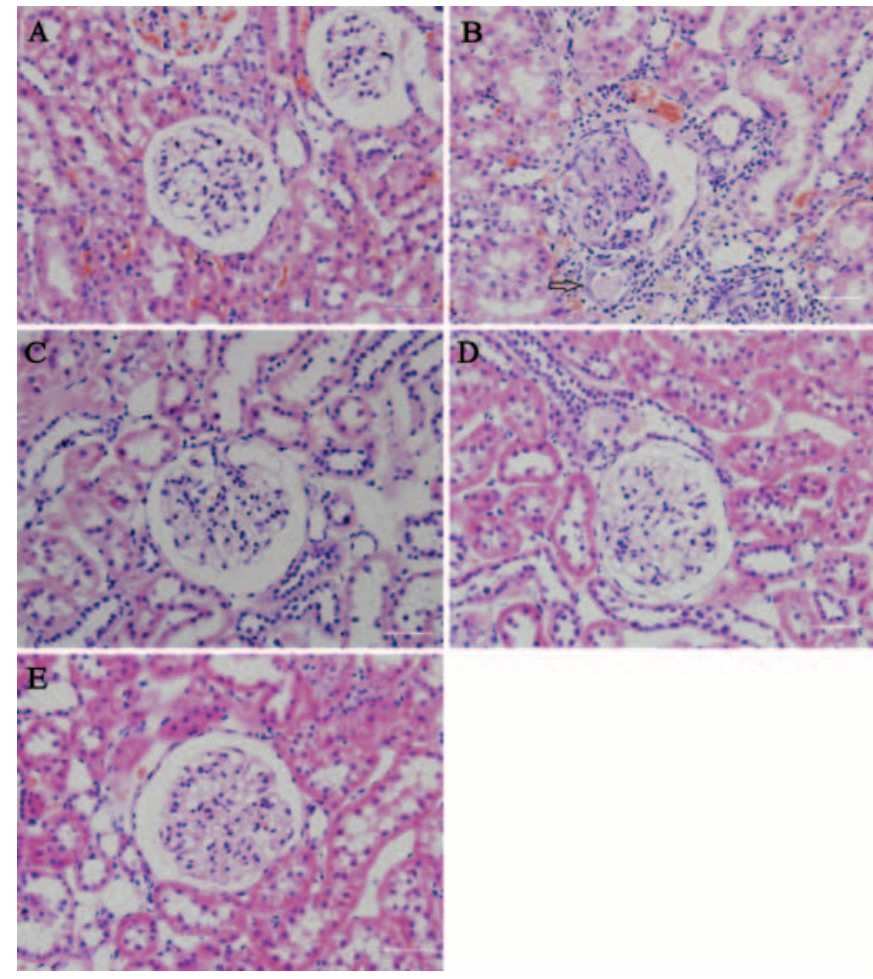

Figure 2. H\&E staining of rat renal tissues. Scale bar, $50 \mu \mathrm{m}$. (A) The normal group showed normal structure of glomeruli and tubules. (B) The hypertension control group showed shrinkage and hardening in individual glomeruli and most capillaries had lumen occlusion. Hyaline degeneration, glomeruluscapsule adhesion, thickening of Bowman's capsule, atrophy of periphery renal tubules and protein casts (black arrow) were also observed. Other renal tubular epithelial cells showed edema, and the renal interstitium showed inflammatory cell infiltration. In the three intervention groups, (C) telmisartan, (D) pyridoxamine and (E) telmisartan and pyridoxamine, the structures of glomeruli were approximately normal. Some of the renal tubular epithelial cells showed edema, but no protein casts were observed.

showed edema, and the renal interstitium showed infiltration of inflammatory cells. The three intervention groups showed normal glomerular structure with edema in certain renal tubular epithelial cells (Fig. 2). The Masson's trichrome staining showed that the glomerular mesangial matrix was increased significantly, and there was increased fibrosis in the periphery of the renal capsule and interstitium. The three intervention groups showed a significant decrease in mesangial matrix proliferation, and there was no increase in fibrous material in the periphery of the renal capsule and interstitium. Positive

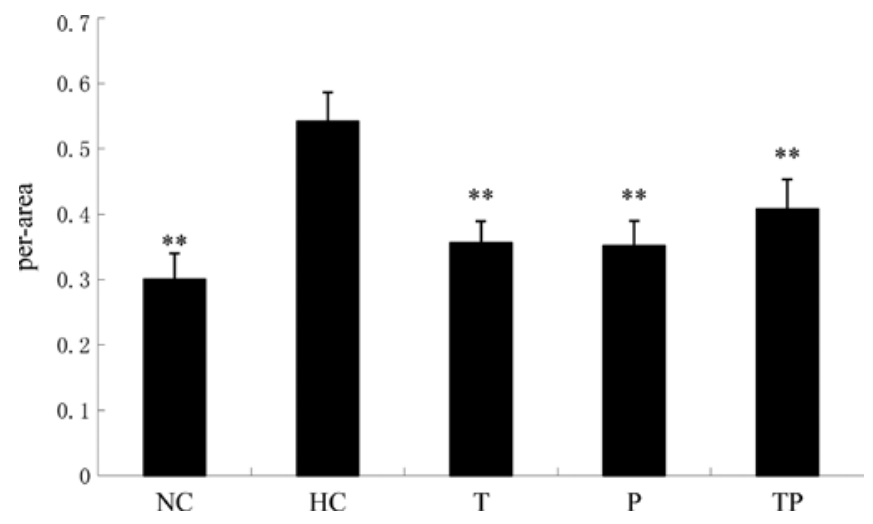

Figure 3. Positive area ratio of glomerular extracellular matrix on Masson's staining of rat renal tissues. NC, normal control; HC, hypertension control; $\mathrm{T}$, telmisartan; $\mathrm{P}$, pyridoxamine; $\mathrm{TP}$, telmisartan and pyridoxamine groups. Data are presented as the means $\pm \mathrm{SD}$ of $5-6$ rats/group. ${ }^{* * *} \mathrm{P}<0.01$ vs. the $\mathrm{HC}$ group.

area ratio of glomerular extracellular matrix is summarized in Fig. 3. In transmission electron microscopy, the basement membrane showed local irregular thickening, with local fusion of podocytic processes and some protein drops in the podocytes. The mesangial region expansion was apparent and the mesangial matrix was increased. Following intervention with pyridoxamine, telmisartan or telmisartan and pyridoxamine, the above abnormalities were improved. No apparent podocytic process fusion was observed, the morphology of the filtration membrane was almost normal, the mesangial matrix increase was insignificant and the brush border of proximal tubular epithelial cells showed tidy alignment with some small vacuoles (Fig. 4).

Immunohistochemical detection of NF- $\kappa B p 65$ and p-ERK1/2 in rat renal tissue. In the $\mathrm{HC}$ group, the cytoplasm of most glomeruli and renal tubules showed a positive NF- $\kappa B p 65$, and some of the nuclei showed a strong positive reaction. In the three intervention groups, some of the renal tubule cells were positive, and the positive areas were mostly located in the cytoplasm. A few podocytes in the glomeruli showed a positive reaction in the cytoplasm (Fig. 5). Nuclear localization of activated ERK1/2 was shown both in the glomeruli and renal tubule cells. The HC group showed a higher MOD of p-ERK1/2 compared to the NC group. In the three intervention 

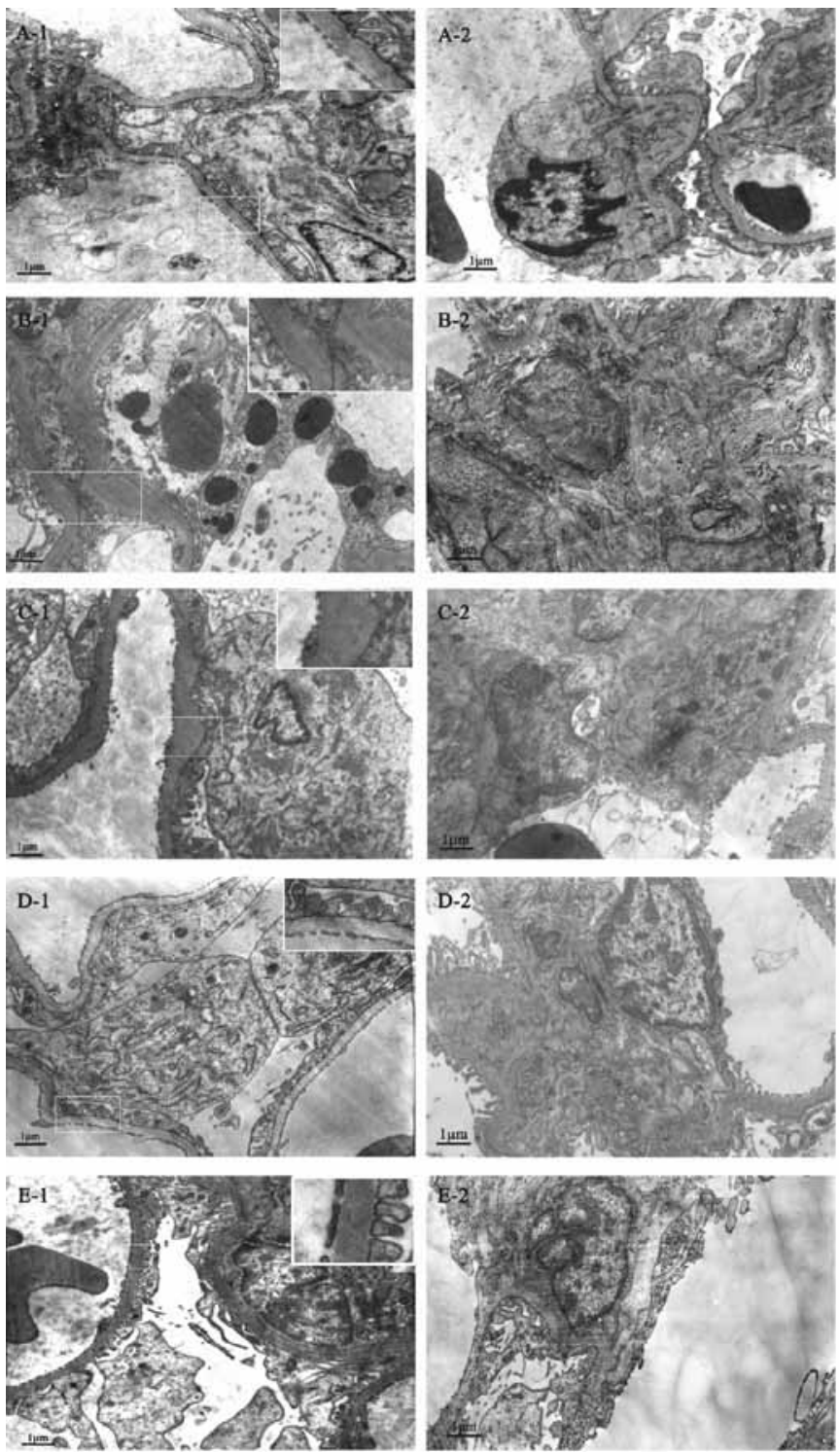

Figure 4. Ultrastructures of rat glomeruli and renal tubules under transmis sion electron microscopy. (A) Normal control; (B) hypertension control; (C) telmisartan; (D) pyridoxamine; (E) telmisartan and pyridoxamine. 1: Glomerular filtration barrier (podocytic process, basement membrane, endothelial fenestrae) (x6,300). 2: Mesangium (mesangial matrix, mesangial cells) (x6,300). Under transmission electron microscopy, the HC group showed irregular local thickening in the basement membrane and local fusion of podocytic processes, where some protein drops were present in the podocytes (B-1). In addition, the mesangium was significantly expanded, and the mesangial matrix increased (B-2). The three intervention groups showed significant improvement in the above abnormalities, and there was no significant fusion of the podocytic processes, nearly-normal morphology of the filtration membrane and no significant increase in the mesangial matrix. Moreover, the brush borders of proximal tubular epithelial cells were regularly aligned, and some small vacuoles were observed in the cells.

groups, less glomeruli and renal tubule cells were positive for p-ERK1/2 (Fig. 6). Summary of the MOD showed that both NF- $\kappa$ Bp 65-positive $(\mathrm{P}<0.01)$ and $\mathrm{p}$-ERK1/2-positive areas $(\mathrm{P}<0.05)$ in the three intervention groups were significantly lower than those in the $\mathrm{HC}$ group. Among the intervention groups, the positive expression of NF-kBp65 ( $\mathrm{P}<0.01$ vs. the $\mathrm{T}$ and $\mathrm{P}$ groups) and that of $\mathrm{p}$-ERK1/2 ( $\mathrm{P}<0.05$ vs. the $\mathrm{P}$ group) was lowest in the TP group (Fig. 7).
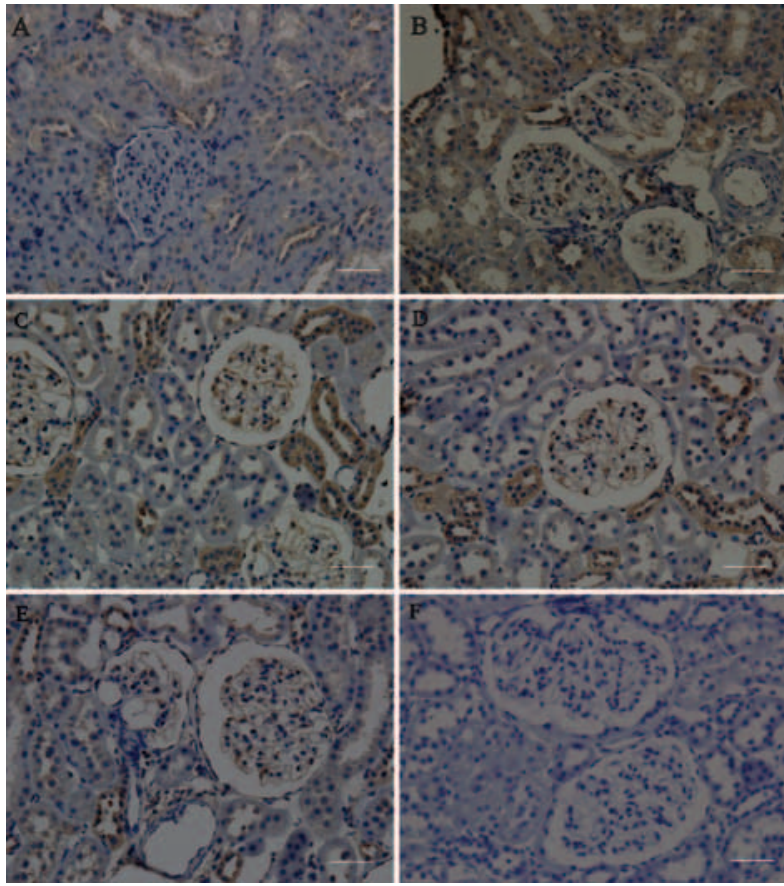

Figure 5. Immunohistochemical detection of nuclear factor $\kappa \mathrm{B}(\mathrm{NF}-\kappa \mathrm{B})$ p65 in rat renal tissue. Scale bar, $50 \mu \mathrm{m}$. Compared to that in the normal group (A), the cytoplasm of most glomeruli and renal tubules in the hypertension control group (B) showed positivity for NF- $\mathrm{kP} 65$, and some of the nuclei showed a strong positive reaction. In the three intervention groups, (C) telmisartan, (D) pyridoxamine and (E) telmisartan + pyridoxamine, fewer glomeruli and renal tubule cells were positive, where the positive areas were mostly in the cytoplasm. (F) Negative control is also shown.

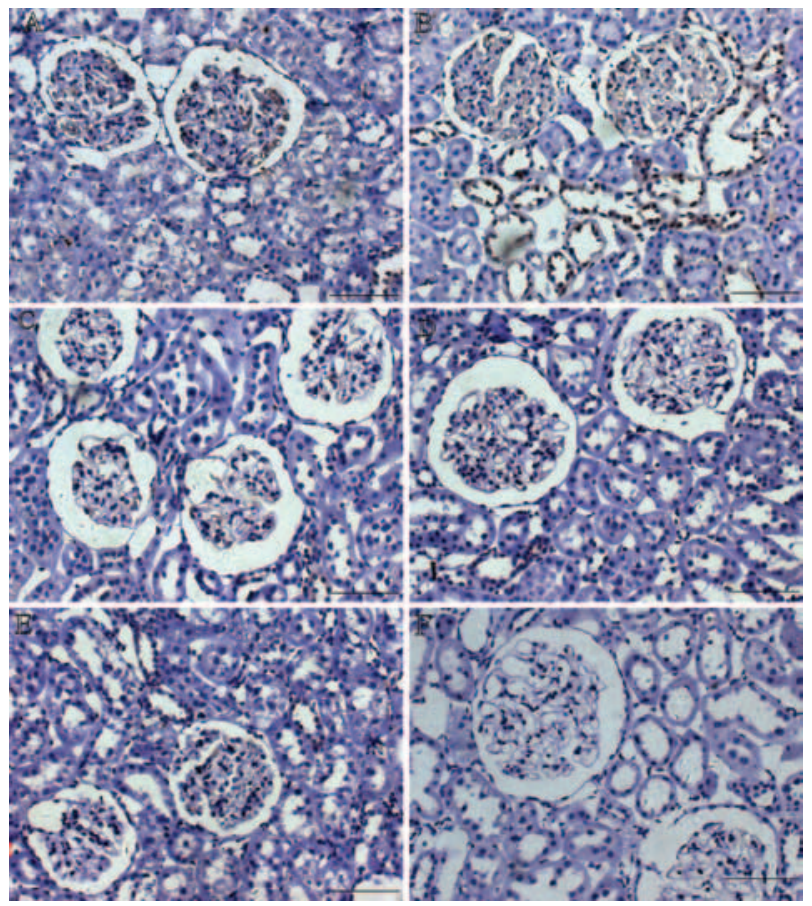

Figure 6. Immunohistochemical detection of phosphorylated extracellular regulated kinase 1/2 (p-ERK1/2) in rat renal tissue. Scale bar, $50 \mu \mathrm{m}$. Nuclear localization of activated ERK1/2 was shown both in the glomeruli and renal tubule cells. The hypertension group (B) showed a higher mean optical density of p-ERK1/2 compared to the normal group (A). In the three intervention groups, (C) telmisartan, (D) pyridoxamine and (E) telmisartan and pyridoxamin, fewer glomeruli and renal tubule cells were positive for p-ERK1/2. Moreover, the positive expression of p-ERK1/2 was lower in the TP group compared to that in the $\mathrm{P}$ group. (F) Negative control was also shown. 


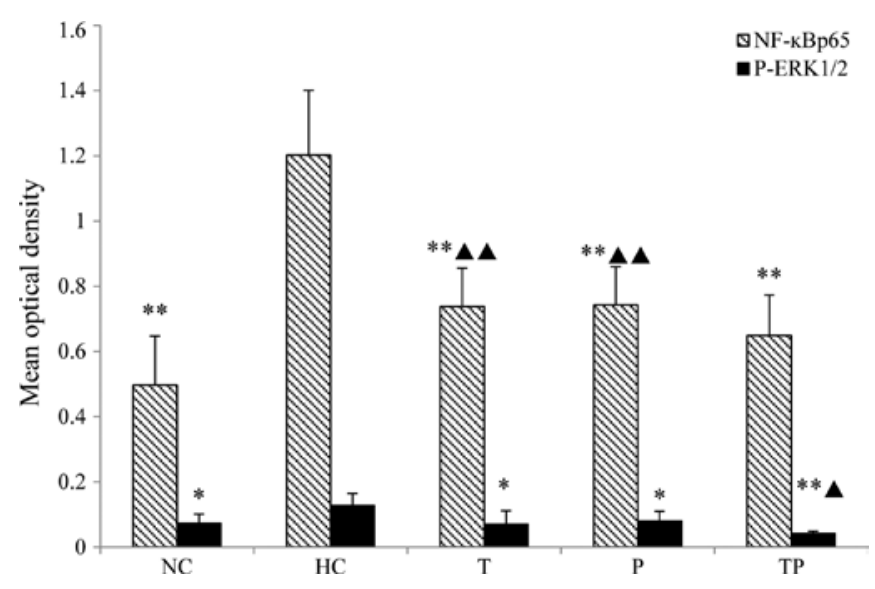

Figure 7. Mean optical density of NF-кBp65 and p-ERK1/2 in rat renal tissues. NC, normal control; HC, hypertension control; T, telmisartan; $\mathrm{P}$, pyridoxamine; TP, telmisartan and pyridoxamine; NF- $\kappa B$, nuclear factor $\kappa \mathrm{B}$; p-ERK1/2, phosphorylated extracellular regulated kinase 1/2. Data are presented as the means $\pm \mathrm{SD}$ of $5-6$ rats/group. ${ }^{*} \mathrm{P}<0.05 ;{ }^{* *} \mathrm{P}<0.01$ vs. the $\mathrm{HC}$ group; ${ }^{\wedge} \mathrm{P}<0.05 ;{ }^{\wedge} \mathrm{P}<0.01$ vs. the TP group.
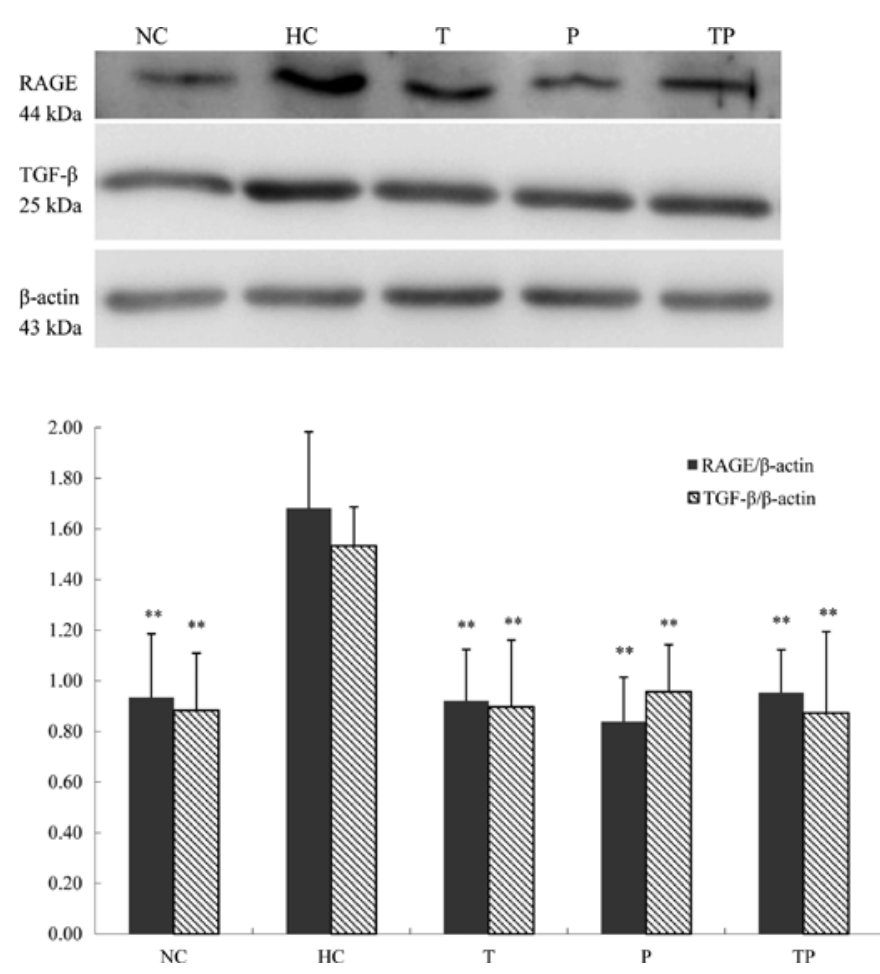

Figure 8. RAGE and TGF- $\beta$ protein expression in rat renal cortex. NC normal control; HC, hypertension control; T, telmisartan; P, pyridoxamine; TP, telmisartan and pyridoxamine; RAGE, receptor for advanced glycation end products; TGF- $\beta$, transforming growth factor- $\beta$. Data are presented as the means $\pm \mathrm{SD}$ of three experiments. ${ }^{* *} \mathrm{P}<0.01$ vs. the $\mathrm{HC}$ group.

Protein expression of RAGE and TGF- $\beta$ in renal tissue. Western blotting results of the protein expression of RAGE and TGF- $\beta$ in the renal cortex in all groups are shown in Fig. 8. The protein expression of RAGE and TGF- $\beta$ in the HC group was higher compared to the $\mathrm{NC}$ group $(\mathrm{P}<0.01)$. The protein expression of RAGE and TGF- $\beta$ in the T,P and TP groups was lower compared to the $\mathrm{HC}$ group $(\mathrm{P}<0.01)$. The expression was not significantly different among the three intervention groups $(\mathrm{P}>0.05)$.

\section{Discussion}

In the present study, 20-week-old SHRs at the early stage of hypertension were selected for the experiment. At the time of sacrifice, the animals were 36 weeks of age, and were at the middle stage of hypertension. In the HC group, glomerular sclerosis was only observed in 1 animal under the light microscope, and no renal artery hyaline degeneration or glomerular sclerosis were observed under transmission electron microscopy. The 24-h urinary albumin in the HC group was significantly higher compared to that in the $\mathrm{NC}$ group, but serum creatinine and urea nitrogen in the $\mathrm{HC}$ group were not significantly different from those in the NC group, suggesting that the SHRs in this experiment were at the stage of early renal damage. The serum levels of AGEs and the expression of renal cortical RAGE in untreated SHRs were significantly higher than those in WKY rats with normal blood pressure, which is consistent with the findings of previous basic and clinical studies $(2,3,17,18)$. The increase in AGEs in the hypertensive state may have been due to an increase in oxygen free radicals promoting the formation of AGE precursors and AGEs, or to a decrease in the renal clearance of AGEs (19). Given that the renal damage in SHRs in this experiment was mild, the increase in AGEs may result from the increase in formation in the body. The levels of urinary albumin in the HC group were significantly higher than those in the NC group, and there was a positive correlation between the concentration of urinary albumin and the serum AGEs. This result is consistent with the findings of Nangaku et al (20). AGEs increased the cross-linkage of components in the glomerular basement membrane, which allowed protein to pass the filter membrane more easily. The filtered albumin accumulated in the mesangial region, thus promoting proliferation of mesangial cells and the accumulation of extracellular matrix (21). Moreover, the up-regulation of RAGE expression aggravated glomerular damage (22).

One of the most significant findings in this study was that pyridoxamine, an AGE formation inhibitor, reduced early renal structural and functional damage in SHRs. Pyridoxamine is one of the three natural forms of vitamin B6. To date, many independent in vitro and in vivo studies have shown that pyridoxamine strongly inhibits the production of AGEs $(12,13)$. Reactive carbonyl compounds are the precursors of AGEs. As a nucleophilic compound, pyridoxamine reacts with carbonyl radicals, inhibiting the formation of AGEs. Pyridoxamine is also a free radical scavenger; it is able to clear ROS produced from biochemical reactions in the body, thereby reducing oxidative stress. Previous studies showed that in Zucker rats, pyridoxamine reduced the levels of AGEs, lowered urine protein concentration, improved hyperlipidemia and preserved renal function (23). Pyridoxamine also lowered AGEs in diabetic STZ rats, significantly inhibited the increase of urine protein and creatinine, and improved hyperlipidemia (24). A phase II clinical trial on the use of pyridoxamine for the treatment of diabetic nephropathy has been completed (25), and a phase III clinical trial is currently in progress (26). However, there have been no previous reports on the protective effects of pyridoxamine on hypertensive renal damage in SHRs. The results of this study showed that the SBP in the P group was not significantly different from that in the HC group, but the level 
of urinary albumin in the $\mathrm{P}$ group was significantly lower than that in the HC group. The morphology of the glomeruli and renal tubules was normal without fibrosis in the renal interstitium in the $\mathrm{P}$ group, which was better than the HC group, but similar to the T group. In addition, the treatment of SHRs with pyridoxamine also reduced the serum levels of AGEs and renal cortical RAGE levels, lowered the amounts of malonaldehyde in the serum and renal cortex, increased the activity of SOD, inhibited the NF- $\mathrm{B}$ and ERK1/2 and decreased the expression of TGF- $\beta$ in the renal cortex.

To the best of our knowledge, this is the first study to report on the preventive properties of pyridoxamine on early hypertensive renal damage in SHRs. Given the beneficial therapeutic effects of pyridoxamine, it could be applied as a supplementary treatment to prevent early renal damage in patients with essential hypertension who are treated with conventional agents to lower blood pressure, especially in those patients with higher levels of AGEs. This would include patients with hypertension and concomitant diabetes, patients with metabolic syndrome and elderly patients with hypertension.

In clinical practice, it is well recognized that telmisartan has protective effects on hypertensive renal damage. Cell culture experiments showed that telmisartan reduced RAGE expression in epithelial cells under an elevated angiotensin II load (7). In the present study, aside from significant blood pressure reduction, the effects of telmisartan were similar to those of pyridoxamine, which included a reduction in serum AGEs and renal cortical RAGE expression, a decrease in malonaldehyde in the serum and renal cortex, an increase of SOD activity, the inhibition of $\mathrm{NF}-\kappa \mathrm{Bp} 65$ and ERK1/2, a reduction of TGF- $\beta$ expression and improvement of early morphological abnormalities in the glomeruli and renal tubules. The mechanisms may include the reduction of blood pressure, the blockage of a series of biological effects after the binding of angiotensin II to AT1 receptors, indirect inhibition of the synthesis of AGEs (7) and the prevention of up-regulation of RAGE by angiotensin II. In addition, it may also partly relate to the PPAR $\gamma$ receptor stimulation by telmisartan, as it has been shown that Thiazolidinediones reduce endothelial expression of RAGE (27).

Davis et al demonstrated that both the ACEI, perindopril and the AGE formation inhibitor, aminoguanidine, retarded the increase in albuminuria in diabetic SHRs. Combination therapy was associated with a superior restoration in diabetesinduced nephrin protein depletion compared to either monotherapy (28). In our study of SHRs, the combined use of telmisartan and pyridoxamine had a more significant effect on the inactivation of $\mathrm{NF}-\kappa \mathrm{B}$ and $\mathrm{ERK} 1 / 2$ in the renal cortex than the single use of either drug. This may have been due to the fact that NF- $\kappa \mathrm{B}$ and ERK1/2 are multi-function transcription factors, and they may be regulated by many other factors, such as ROS, angiotensin II and PKC. Furthermore, there is an auto-negative feedback mechanism after NF- $\kappa$ B activation. Thus, the combined use of telmisartan and pyridoxamine may function through multiple pathways to inhibit the activation of NF- $\kappa$ Bp56 and ERK1/2. An important finding of this study was that the improvement of serum AGEs and renal cortical RAGE expression, and the elevation of SOD activity was superior with pyridoxamine than with telmisartan. This may have been due to the fact that pyridoxamine inhibited the synthesis of AGEs and cleared ROS directly, whereas telmisartan acted by blocking angiotensin II binding to its receptor, which indirectly inhibited the production of ROS. However, there was no synergistic effect of the simultaneous application of these two drugs on serum AGEs, renal cortical RAGE expression. It is evident that renin-angiotensin system blockade and AGE inhibition have specific effects. Several of their downstream effects appear to be similar, suggesting that their renoprotective benefits may ultimately involve common pathways (29).

In conclusion, the single and combined use of telmisartan and pyridoxamine significantly reduced the level of 24-h urinary albumin and reduced pathological changes in the glomeruli and renal interstitium. The combined use of telmisartan and pyridoxamine was superior to the single use of either drug, which could be applied as supplementary treatment to prevent early renal damage in patients with higher levels of AGEs. This would include patients with hypertension, diabetes and metabolic syndrome.

\section{Acknowledgements}

This study was supported by the Nature Science Foundation of Fujian Province (2010J01127).

\section{References}

1. Wang $\mathrm{X}$, Jia $\mathrm{X}$, Chang $\mathrm{T}$ Desai $\mathrm{K}$ and $\mathrm{Wu} \mathrm{L}$ : Attenuation of hypertension development by scavenging methylglyoxal in fructose-treated rats. J Hypertens 26: 765-772, 2008.

2. Desai K and Wu L: Methylglyoxal and advanced glycation endproducts: new therapeutic horizons. Recent Pat Cardiovasc Drug Discov 2: 89-99, 2007.

3. Baumann M, Stehouwer C, Scheijen J, Heemann U, Struijker Boudier H and Schalkwijk C: Nepsilon-(carboxymethyl) lysine during the early development of hypertension. Ann NY Acad Sci 1126: 201-204, 2008.

4. McNulty M, Mahmud A and Feely J: Advanced glycation end-products and arterial stiffness in hypertension. Am J Hypertens 20: 242-247, 2007

5. Busch M, Franke S, Rüster C and Wolf G: Advanced glycation end-products and the kidney. Eur J Clin Invest 40: 742-755, 2010.

6. Koka V, Wang W, Huang XR, Kim-Mitsuyama S, Truong LD and Lan HY: Advanced glycation end products activate a chymasedependent angiotensin II - generating pathway in diabetic complications. Circulation 113: 1353-1360, 2006.

7. Nakamura K, Yamagishi S, Nakamura Y, Takenaka K, Matsui T, Jinnouchi Y and Imaizumi T: Telmisartan inhibits expression of a receptor for advanced glycation end products (RAGE) in angiotensin-II-exposed endothelial cells and decreases serum levels of soluble RAGE in patients with essential hypertension. Microvasc Res 70: 137-141, 2005.

8. Müller-Krebs S, Kihm LP, Zeier B, Gross ML, Wieslander A, Haug U, Zeier $M$ and Schwenger V: Glucose degradation products result in cardiovascular toxicity in a rat model of renal failure. Perit Dial Int 30: 35-40, 2010.

9. Yamagishi S: Advanced glycation end products and receptoroxidative stress system in diabetic vascular complications. Ther Apher Dial 13: 534-539, 2009.

10. Geronikaki A, Gavalas A, Dislian V and Giannoglou G: Inhibition of renin-angiotensin system and advanced glycation end products formation: a promising therapeutic approach targeting on cardiovascular diseases. Cardiovasc Hematol Agents Med Chem 5: 249-264, 2007.

11. Chang T and Wu L: Methylglyoxal, oxidative stress, and hypertension. Can J Physiol Pharmacol 84: 1229-1238, 2006.

12. Voziyan PA, Metz TO, Baynes JW and Hudson BG: A postAmadori inhibitor pyridoxamine also inhibits chemical modification of proteins by scavenging carbonyl intermediates of carbohydrate and lipid degradation. J Biol Chem 277: 3397-3403, 2002. 
13. Culbertson SM, Enright GD and Ingold KU: Synthesis of a novel radical trapping and carbonyl group trapping anti-AGE agent: a pyridoxamine analogue for inhibiting advanced glycation (AGE) and lipoxidation (ALE) end products. Org Lett 5: 2659-2662, 2003.

14. Kakuta H, Sudoh K, Sasamata M and Yamagishi S: Telmisartan has the strongest binding affinity to angiotensin II type 1 receptor: comparison with other angiotensin II type 1 receptor blockers. Int J Clin Pharmacol Res 25: 41-46, 2005.

15. Yamamoto K, Ohishi M, Ho C, Kurtz TW and Rakugi H: Telmisartan-induced inhibition of vascular cell proliferation beyond angiotensin receptor blockade and peroxisome proliferator-activated receptor-gamma activation. Hypertension 54: $1353-1359,2009$

16. Zheng F, Zeng YJ, Plati AR, Elliot SJ, Berho M, Potier M, Striker LJ and Striker GE: Combined AGE inhibition and ACEi decreases the progression of established diabetic nephropathy in B6 db/db mice. Kidney Int 70: 507-514, 2006.

17. Wu L and Juurlink BH: Increased methylglyoxal and oxidative stress in hypertensive rat vascular smooth muscle cells. Hypertension 39: 809-814, 2002.

18. Wang X, Desai K, Clausen JT, et al: Increased methylglyoxal and advanced glycation end products in kidney from spontaneously hypertensive rats. Kidney Int 66: 2315-2321, 2004

19. Singh R, Barden A, Mori T and Wu L: Advanced glycation endproducts: a review. Diabetologia 44: 129-146, 2001.

20. Nangaku M, Miyata T, Sada T, Mizuno M, Inagi R, Ueda Y, Ishikawa N, Yuzawa H, Koike H, van Ypersele de Strihou C and Kurokawa K: Anti-hypertensive agents inhibit in vivo the formation of advanced glycation end products and improve renal damage in a type 2 diabetic nephropathy rat model. Am Soc Nephrol 14: 1212-1222, 2003.

21. Yang CW, Vlassara H, Peten EP, He CJ, Striker GE and Striker LJ: Advanced glycation end products up-regulate gene expression found in diabetic glomerular disease. Proc Natl Acad Sci USA 91: 9436-9440, 1994

22. Yamamoto Y, Kato I, Doi T, Yonekura H, Ohashi S, Takeuchi M, Watanabe T, Yamagishi S, Sakurai S, Takasawa S, Okamoto H and Yamamoto H: Development and prevention of advanced diabetic nephropathy in RAGE-overexpressing mice. J Clin Invest 108: 261-268, 2001.
23. Alderson NL, Chachich ME, Youssef NN, Beattie RJ Nachtigal M, Thorpe SR and Baynes JW: The AGE inhibitor pyridoxamine inhibits lipemia and development of renal and vascular disease in Zucker obese rats. Kidney Int 63: 2123-2133, 2003.

24. Thorsten P, Degenhardt, Nathan L, Beattie RJ, Basgen JM, Steffes MW, Thorpe SR and Baynes JW: Pyridoxamine inhibits early renal disease and dyslipidemia in the streptozotocindiabetic rat. Kidney Int 61: 939-950, 2002.

25. Williams ME, Bolton WK, Khalifah RG, Degenhardt TP Schotzinger RJ and McGill JB: Effects of pyridoxamine in combined phase 2 studies of patients with type 1 and type 2 diabetes and overt nephropathy. Am J Nephrol 27: 605-614, 2007.

26. Chetyrkin SV, Zhang W, Hudson BG, Serianni AS and Voziyan PA: Pyridoxamine protects proteins from functional damage by 3-deoxyglucosone: mechanism of action of pyridoxamine. Biochemistry 47: 997-1006, 2008.

27. Marx N, Walcher D, Ivanova N, Rautzenberg K and Jung A: Thiazolidinediones reduce endothelial expression of receptors for advanced glycation end products. Diabetes 53: 2662-2668, 2004.

28. Davis BJ, Forbes JM, Thomas MC, Jerums G, Burns WC, Kawachi H, Allen TJ and Cooper ME: Superior renoprotective effects of combination therapy with ACE and AGE inhibition in the diabetic spontaneously hypertensive rat. Diabetologia 47: 89-97, 2004.

29. Coughlan MT, Thallas-Bonke V, Pete J, Long DM and Gasser A: Combination therapy with the advanced glycation end product cross-link breaker, alagebrium, and angiotensin converting enzyme inhibitors in diabetes: synergy or redundancy? Endocrinology 148: 886-895, 2007. 